ISSN: 2617-6548

\title{
Effect of Cutting Size, Number of Buds and Potatoes on Sprouting and Adventitious Root Formation of Rose Semi Hardwood Cuttings
}

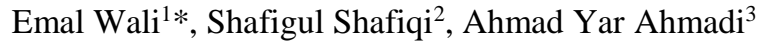 \\ ${ }^{1,2,3}$ Faculty of Agriculture, Shaikh Zayed University, Khost, Afghanistan \\ *Corresponding author: Emal Wali (emal.wali@yahoo.com)
}

\begin{abstract}
In this experiment the combined effect of cutting size $(15,20$ and $25 \mathrm{~cm})$, number of buds on cuttings $(1,2$ and 3$)$ and planting soft wood cutting in potatoes and without potatoes was studied relative to the sprouting of axillary buds and adventitious root formation of 3 months old rose semi hardwood cuttings. The experiment was replicated at two different times. First, the experiment was conducted in 2016 to study the effects of high elevation. Furthermore, the roses were cultivated in high elevation and was planted in low elevation. While in the second experiment the roses were cultivated in low elevation and was planted in the same elevation. In the first experiment, even though, most of the cuttings sprouted in the initial stage of development, but none of them produced roots. In the second experiment, cuttings planted in soil, leaves were developed and also most of them produced roots, while those cutting planted in potatoes, most of the cuttings sprouted in the initial stage of development, but none of them produced roots. In terms of cutting size and bud number, from the second experiment it was revealed that the numbers of bud and cutting size have significant effects on both shoot length ( $<0.001),(p=0.009)$ and root formation ( $p<0.001),(p=0.022)$, respectively. It was also found out that the two factors together (bud number and cutting size) have significant effect ( $<$ 0.001) on both shoot elongation and root formation. The test of least significant difference (LSD) suggested that those treatments having $15 \mathrm{~cm}$ cutting size and 2 buds are significantly different in terms of both sprouting and roots formation.
\end{abstract}

Keywords: Adventitious root formation; Axillary bud-break; Pot rose; Semi hardwood cutting.

DOI: $10.53894 /$ ijirss.v2i4.21

Funding: This research was funded by the World Bank under the higher education development program, grant number P146184".

History: Received: 4 October 2019/Revised: 18 November 2019/Accepted: 18 December 2019/Published: 17 December 2019

Licensed: This work is licensed under a Creative Commons Attribution 4.0 License $(\mathrm{cc}) \mathrm{EY}$

Acknowledgement: The authors are grateful to the Ministry of Higher Education (MOHE), Afghanistan and World Bank for supporting this research.

Competing Interests: The authors declare that they have no conflict of interests.

Transparency: The authors confirm that the manuscript is an honest, accurate, and transparent account of the study was reported; that no vital features of the study have been omitted; and that any discrepancies from the study as planned have been explained.

Ethical: This study follows all ethical practices during writing. 


\section{Introduction}

Pot roses are grown in 8-12-week cycles[1]. Root formation and axillary bud growth are the initial growth of vegetatively propagated plants. Vegetative propagation is a good method for producing large numbers of uniform plants, however, it is not always successful because of the variation in root formation and further growth can be observed [1,2]. The inhomogeneity may be caused by variation in the formation and development of roots [3] and in the onset of axillary bud growth [4, 5]. Moreover, mineral contents specifically nitrogen and the amount of carbohydrate in the cuttings have a significant effects on the formation of adventitious roots [6]. Carbohydrates help support the formation of adventitious roots by providing energy and the carbon essential for cell division, new roots meristems and root formation [7]. Taking into account these arguments, it is assumed that potatoes would provide the initial carbohydrate for the rose cutting to produce roots. Studies reported that in rose, axillary sprout length is positively correlated with root weight of cuttings. However, it is not clear whether the axillary bud growth is caused by root formation or not [2].

Afghanistan is a country having a huge amount of agriculturally productive soils where farmers can grow various types of crops, but unfortunately due to the insufficient soil and crops information, farmers are not able to decide growing different types of crops. Khost province is one of those provinces where mono-cropping system is accustomed [8]. Most of the farmers around Khost, cultivate only wheat, maize and rice in the province. The idea of rose production and cultivation has already been in the mind of farmers, but the problem is having insufficient rose's propagation information and the techniques which have to be considered during the vegetative reproduction of roses. A well developed and systematic rose's production system first needs the knowledge of vegetative and reproductive propagation of roses. As in vegetative production of roses the primary objective is the root and shoot formation of a cutting. Therefore, our objective of the present work is to investigate the effects of cutting size, number of buds and the use of potatoes on roots formation and sprouting. When the terminal flower bud is visible on a rose shoot, the axillary buds on that shoot contain more than $50 \%$ of the final leaf primordia so they may be regarded as ontogenetically mature for use in cuttings. At that time, the auxin export from the apex might decrease [9].

In rose, the position of the cutting on the stock plant affects root formation [10,11] and axillary bud growth [4, 12]. Also, the length of the stem below the node of the cutting influences root formation and axillary bud growth [11], and generally, cutting morphology and stored photosynthates influence rooting [13]. In rose, exogenous auxins advance root formation [1, 10, 11, 14]. Dieleman, et al. [9] proposes a positive role for endogenous cytokinins in axillary bud growth [9]. Still no scientific study has been conducted on rose's propagation in Khost province of Afghanistan. Since rose is a high value plant that can return more revenues than other field crops e.g. wheat, rice and maize. Conducting such a systematic experiment could reveal the chances of low cost rose's production.

\section{Materials and Methods}

This research was conducted to find out the most effective, easy and economic ways of rose's propagation. Rose's production and the business of roses is a type of business that can shift the current mono-cropping system of Khost province into more complex agricultural system. In this research two experiments were conducted. Roses were cultivated in area of high elevation $(2500 \mathrm{~m})$ above sea level in the first experiment. The cuttings were planted in area that has low elevation $(900 \mathrm{~m})$ above sea level, while in the second experiment cuttings were prepared from areas of low elevation and were planted in the same area. For the first experiment the cuttings were taken from rose plants cultivated in rose garden located near governor office, Paktya province, while for the second experiment, rose plants were raised in the research farm of agriculture faculty, Shaikh Zayed University. The cuttings were taken in winter. It was kept moist under soil. At the beginning of the experiment the following hypothesis were considered.

Both cutting size and bud number have significant effects on sprouting and adventitious root formation.

$$
\begin{aligned}
& H_{0}: \mu=1 \\
& H_{1}: \mu \neq 1
\end{aligned}
$$

The use of potatoes has significant effects on sprouting and adventitious root formation of rose's Semi hardwood cuttings.

$$
\begin{aligned}
& H_{0}: \mu=1 \\
& H_{1}: \mu \neq 1
\end{aligned}
$$

In both experiments, 9 treatments were assigned to eight blocks randomly. Each block containing 9 cuttings. Each experiment was replicated three times during the same period. The cuttings were cultivated in four blocks with potatoes and four blocks without potatoes. Analyses of variance was carried out for 1) length of the sprout from the main axillary bud after 3 months, and 2) oven dried weight of roots after 3 months. Each treatment received similar amount of sunlight, soil conditions, temperature, water, irrigation times and other environmental factors. Only the effects of the cutting size, bud number and the use of potatoes were studied against the number of roses that produce roots and shouts. In this experiment the combined effect of cutting size $(15,20$ and $25 \mathrm{~cm}$ ), number of buds on cuttings (1,2 and 3) and planting cuttings with potatoes and without potatoes have been studied relative to the sprouting of axillary buds and adventitious root formation of 3 months old rose semi hardwood cuttings Table 1. 
Table-1.

Treatments applied randomly to the experimental units.

\begin{tabular}{l|c}
\hline Treatments & Details \\
\hline A & $15 \mathrm{~cm}$ and Bud 1 (with potato) \\
\hline B & $15 \mathrm{~cm}$ and Bud 2 (with potato) \\
\hline $\mathrm{C}$ & $15 \mathrm{~cm}$ and Bud 3 (with potato) \\
\hline $\mathrm{D}$ & $20 \mathrm{~cm}$ and Bud 1 (with potato) \\
\hline $\mathrm{E}$ & $20 \mathrm{~cm}$ and Bud 2 (with potato) \\
\hline $\mathrm{F}$ & $20 \mathrm{~cm}$ and Bud 3 (with potato) \\
\hline $\mathrm{G}$ & $25 \mathrm{~cm}$ and Bud 1 (with potato) \\
\hline $\mathrm{H}$ & $25 \mathrm{~cm}$ and Bud 2 (with potato) \\
\hline $\mathrm{I}$ & $25 \mathrm{~cm}$ and Bud 3 (with potato) \\
\hline
\end{tabular}

Randomized Completely Block Design (RCBD) was considered Table 1. All of the 9 treatments in Table 1 were assigned randomly as Figure 1 .

\begin{tabular}{|c|c|c|c|c|c|c|c|}
\hline \multicolumn{2}{|c|}{ B-1 } & \multicolumn{2}{|c|}{ B-2 } & \multicolumn{2}{|c|}{ B-3 } & \multicolumn{2}{|c|}{ B-4 } \\
\hline C & 1 & F & 10 & D & 19 & B & 28 \\
\hline I & 2 & I & 11 & E & 20 & $\mathrm{H}$ & 29 \\
\hline F & 3 & C & 12 & $F$ & 21 & C & 30 \\
\hline H & 4 & $E$ & 13 & & 22 & G & 31 \\
\hline A & 5 & & 14 & & 23 & A & 32 \\
\hline$E$ & 6 & $\mathrm{H}$ & 15 & I & 24 & I & 33 \\
\hline B & 7 & D & 16 & B & 25 & D & 34 \\
\hline G & 8 & $\mathrm{G}$ & 17 & $\underline{\mathrm{H}}$ & 26 & $E$ & 35 \\
\hline D & 9 & B & 18 & C & 27 & F & 36 \\
\hline
\end{tabular}

Figure-1.

Randomly assigned treatments to blocks.

\section{Results}

\subsection{First Experiment}

Sprouting

A few days after planting, the main axillary bud of most cuttings broke and developed into the main sprout; in some treatments more than one sprout developed. After 21 days the main sprout always bore a number of leaves, while in several of the longest ones the apical flower bud was already visible. After 45 days most of the axillary buds were dried and shoot development stopped.

\section{Adventitious Root formation}

After 45 days, all of the cuttings were removed from the pots. There is no root development. The cutting ends were spoiled, and only dead tissues were remained Figure 2.

The suitable planting time in Khost province for rose cutting is 15 March. This time was passed. The cuttings were planted on May 15, 2017. The roses in Khost province were sprouted at that time. It has to be in a dormant condition when planting rose cuttings. We decided to use un-sprouted cuttings from colder region of Afghanistan to study the effects of elevation. The results are negative in the first experiment. It means that both cultivation time and elevation gradient is very important for rose cuttings to produce roots. Therefore, the whole experiment was replicated again.

\subsection{Second Experiment}

The second experiment was conducted on 15 March, 2018. This time similar species of roses were selected from the research farm of agriculture faculty. The cutting were planted in small open fields. Our aim was to study the effects of cutting size, bud numbers and cultivation with potatoes and without potatoes. In the second experiment cuttings cultivated with potatoes neither sprouted nor produced any roots, therefore, it is difficult to claim that potatoes have significant role in rose cutting root formation. In the experiment without the use of potatoes, most of the cuttings produced roots and shouts. The details are described in the following paragraphs. 


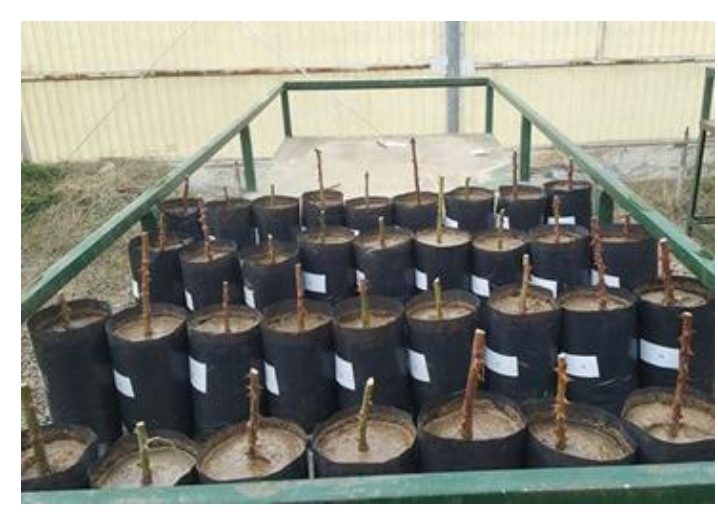

(a)

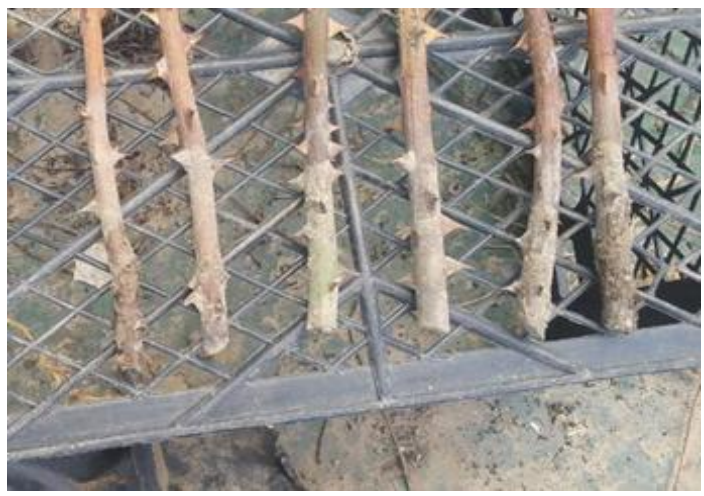

(b)

Figure-2.

(a) Beginning of planting and (b) after 45 days of planting.

\section{Sprouting}

A few days after planting, the main axillary bud of most cuttings broke and developed into the main sprout; in some treatments more than one sprout developed. After 21 days the main sprout always bore a number of leaves, while in several of the longest ones the apical flower bud was already visible. After 90 days most of the axillary buds were developed and the cuttings were in good conditions. The effects of bud number and cutting size on bud elongation in $\mathrm{cm}$ and root formation after 90 days were studied. Table 2 shows the analysis of variance.

Table-2.

Analysis of variance table for shoot length.

\begin{tabular}{l|l|l|l|l|l}
\hline Source & DF & SS & MS & F & P \\
\hline Replication & 2 & 21.67 & 10.836 & - & - \\
\hline Block & 3 & 423.17 & 141.058 & - & - \\
\hline Bud No. & 2 & 535.28 & 267.638 & 13.59 & $<0.001^{*}$ \\
\hline Cutting size & 2 & 193.89 & 96.944 & 4.92 & $0.0094^{*}$ \\
\hline Bud No*Cutting size & 4 & 1386.85 & 346.714 & 17.61 & $<0.001^{*}$ \\
\hline Error & 88 & 1732.89 & 19.692 & - & - \\
\hline Total & 107 & 4295.21 & - & - & - \\
\hline
\end{tabular}

Note: Grand mean 5.2769, CV 84.09

DF (degrees of freedom), SS (sum of squares), MS (mean sum of squares), F (F-statistic), P (P-value).

Table 2 shows that the number of buds and cutting size have significant effects on the shoot elongation after cultivation. The $\mathrm{P}$ value for bud number and cutting size is less than 0.05 alpha level. It was concluded that there is significant difference among treatments in bud number and cutting size, but treatments with bud number have more significant effects than cutting size on shoot elongation. To understand which treatments are significantly different, the least significant difference (LSD) test between the treatments of cutting size and bud number was performed.

The results are presented in a triangular matrix format Table 3 . The triangular matrix identifies means that are significantly different. The treatment levels are listed along the top and down the left side of the table. The values in the body of the table are differences between pairs of means. The critical value for a comparison, 3.6002, is the minimum difference between two means needed for significance.

Pairs that are significantly different are flagged with an asterisk. Table 3 displays the LSD all-pairwise comparisons test of shoot length for bud number*cutting size. Alpha: 0.05, Standard Error for Comparison: 1.8116, Critical T Value: 1.987, Critical Value for Comparison: 3.6002

* Represent treatments that are significantly different.

\section{Adventitious root formation}

After 90 days, all of the cuttings were removed from the pots. Most of the cuttings produced good amount of roots. All of the cuttings were washed in water and the roots of each cutting were cut and weighted both fresh and oven dried. The effects of bud number and cutting size on the roots formation was studied after 90 days. Table 4 shows the analysis of variance. 
Table-3.

LSD all-pairwise comparisons test of shoot length for bud number*cutting size.

\begin{tabular}{|c|c|c|c|c|c|c|c|c|c|c|}
\hline $\begin{array}{l}\text { Bud } \\
\text { No. }\end{array}$ & $\begin{array}{c}\text { Cutting Size } \\
(\mathrm{cm})\end{array}$ & Mean & 15,15 & 1,20 & 1,25 & 2,15 & 2,20 & 2,25 & 3,15 & 3,20 \\
\hline 1 & 15 & 1.150 & & & & & & & & \\
\hline 1 & 20 & 3.975 & 2.825 & & & & & & & \\
\hline 1 & 25 & 3.075 & 1.925 & 0.900 & & & & & & \\
\hline 2 & 15 & 16.417 & $15.267 *$ & $12.44 *$ & $13.342 *$ & & & & & \\
\hline 2 & 20 & 2.450 & 1.300 & 1.525 & 0.625 & $13.967 *$ & & & & \\
\hline 2 & 25 & 5.600 & $4.450 *$ & 1.625 & 2.525 & $10.817 *$ & 3.150 & & & \\
\hline 3 & 15 & 2.375 & 1.225 & 1.600 & 0.700 & $14.042 *$ & 0.075 & 3.225 & & \\
\hline 3 & 20 & 3.950 & 2.800 & 0.025 & 0.875 & $12.467 *$ & 1.500 & 1.650 & 1.575 & \\
\hline 3 & 25 & 8.500 & $7.350 *$ & $4.525^{*}$ & $5.425^{*}$ & 7.917* & $6.050 *$ & 2.900 & $6.125^{*}$ & $4.550 *$ \\
\hline
\end{tabular}

Table-4.

Analysis of variance table for roots formation.

\begin{tabular}{l|l|l|l|l|l}
\hline Source & DF & SS & MS & F & P \\
\hline Replication & 2 & 630 & 315.1 & & \\
\hline Block & 3 & 61893 & 20631 & & \\
\hline Bud No. & 2 & 73888 & 36944 & 13.15 & $<0.001^{*}$ \\
\hline Cutting size & 2 & 22357 & 11178.5 & 3.98 & $0.0222^{*}$ \\
\hline $\begin{array}{l}\text { Bud No*Cutting } \\
\text { size }\end{array}$ & 4 & 127685 & 31921.2 & 11.36 & $<0.001^{*}$ \\
\hline Error & 88 & 247195 & 2809 & & \\
\hline Total & 107 & 533704 & & & \\
\hline $\begin{array}{l}\text { Note: Grand Mean 49.148, CV: } 107.84 \\
\text { DF (degrees of freedom), SS (sum of squares), MS (mean sum of squares), F (F-statistic), P (P-value) }\end{array}$
\end{tabular}

Table 4 shows that the number of buds and cutting size have significant effects on the roots formation and elongation after cultivation. The $\mathrm{P}$ value for bud number and cutting size is less than 0.05 alpha level. It was concluded that there is significant difference among treatments in bud number and cutting size, but treatments with bud number have more significant effects than cutting size on roots formation and elongation. The effects of both cutting size and bud number is also significant; therefore, the test of least significant difference (LSD) was performed to understand, which treatments are more significant in terms of both factors. The results of LSD are presented in a triangular matrix format Table 5.

Table-5.

LSD all-pairwise comparisons test of oven dried weight of roots for bud number*cutting size.

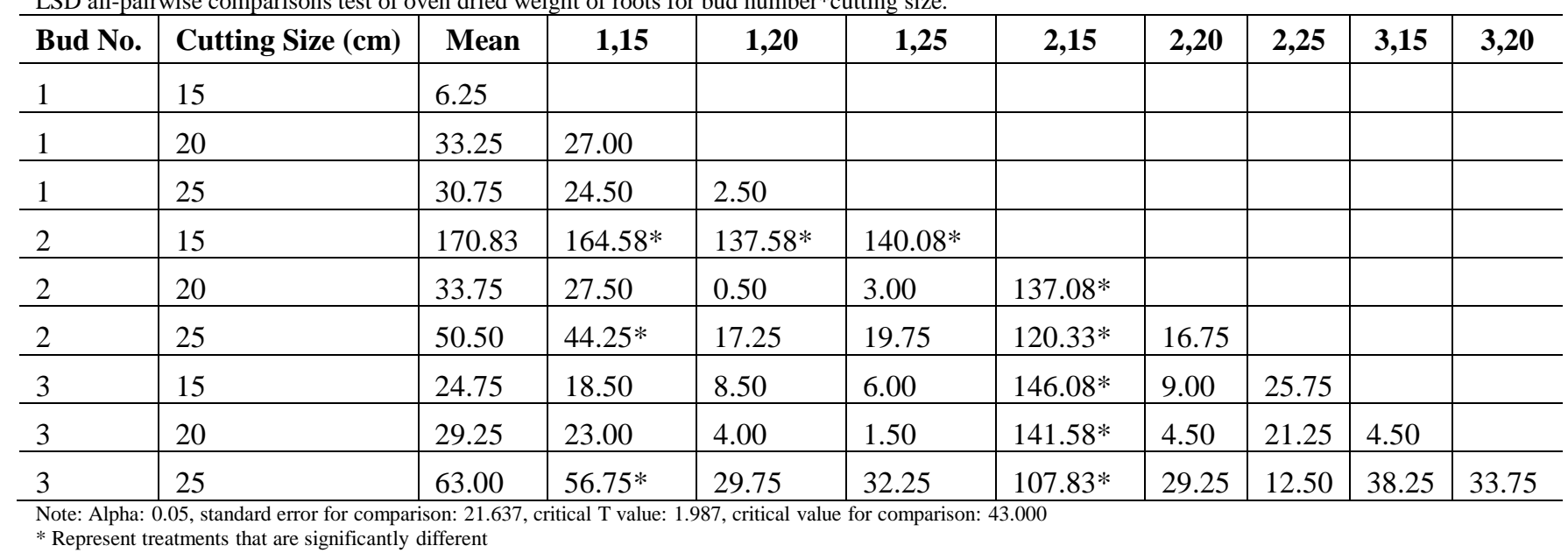

\section{Discussion}

\subsection{Sprouting}

The initial assumptions for the first experiment was to study the effects of high elevation and low elevation on semi hardwood rose cutting roots formation and also It was assumed that potatoes could provide sustained moisture and initial carbohydrates for the cuttings to root. Very little is known about the effects of high and low elevation on rose cuttings 
adventitious roots formation. The sudden change of temperature may have caused the rose cutting to stop its growth and development. In our first experiment it was difficult to accept that elevation gradient does not have or have little effects on rose cuttings roots formation, because none of the cutting sprouted. While from the second experiment only those cuttings planted in soil, most of them sprouted and those planted in potatoes, none of them were able sprout, however, there is a common belief and some researchers [15] think that potatoes provide the right amount of nutrients and moisture to rose cuttings, therefore, to develop roots.

\subsection{Adventitious Root Formation}

In terms of adventitious root formation, similar results were obtained as the sprouting from the first experiment. While from the second experiment only those cuttings planted in soil, most of them produced roots and those planted in potatoes, none of them were able produce roots. It was difficult to accept the assumption that potatoes help rose cutting to produce better roots. Analysis of variance was carried out for the remaining 108 cuttings in three replications. These remaining cuttings were cultivated in soil. Table 4 shows that both factors cutting size and bud number have significant effects on the semi hardwood rose cutting adventitious roots formation, but the effects of bud number are more when compared to cutting size. Further analysis was needed to find out which treatments are more significant. Table 5 represents the least significant difference (LSD) test results. The results show that treatments having 2 buds and $15 \mathrm{~cm}$ cutting size, when compared to treatments having $1 \mathrm{bud}, 15 \mathrm{~cm}, 1 \mathrm{bud}, 20 \mathrm{~cm}, 1 \mathrm{bud}, 25 \mathrm{~cm}, 2 \mathrm{buds}, 20 \mathrm{~cm}, 2 \mathrm{buds}, 25 \mathrm{~cm}, 3 \mathrm{buds}, 15 \mathrm{~cm}, 3 \mathrm{bud}, 20 \mathrm{~cm}$ and 3 buds, $25 \mathrm{~cm}$ are significantly different than other treatments.

\section{Conclusion}

The first experiment determined that elevation has significant effects on sprouting and adventitious root formation. It was decided to use un-sprouted cuttings from colder areas of Afghanistan and see the effects of another area. The results are negative in the first experiment. It means that both cultivation time and elevation gradient is very important for rose cuttings to produce roots. In the second experiment, those cuttings planted in potatoes produced neither roots nor sprouted. Therefore, it was difficult to accept our null hypothesis that the use of potatoes has significant effects on sprouting and root formation. In terms of cutting size and bud number, from the second experiment it was understood that the number of buds and cutting size have significant effects on both roots formation and sprouting after cultivation. It was also found out that the two factors together (bud number and cutting size) has significant effect $(\mathrm{p}<0.001)$ on both shoot elongation and root formation. The LSD suggest that those treatments having $15 \mathrm{~cm}$ cutting size and 2 buds are significantly different in terms of both sprouting and roots formation.

\section{References}

[1] D. De Vries and L. A. Dubois, "The effect of BAP and IBA on sprouting and adventitious root formation of 'Amanda'rose single-node softwood cuttings," Scientia Horticulturae, vol. 34, pp. 115-121, 1988.Available at: https://doi.org/10.1016/03044238(88)90081-7.

[2] L. A. Dubois and D. De Vries, "Variation in adventitious root formation of softwood cuttings of Rosa chinensis minima (Sims) Voss cultivars," Scientia Horticulturae, vol. 47, pp. 345-349, 1991.Available at: https://doi.org/10.1016/0304-4238(91)90018t.

[3] J. Hansen and K. Kristensen, "Axillary bud growth in relation to adventitious root formation in cuttings," Physiologia Plantarum, vol. 79, pp. 39-44, 1990.Available at: https://doi.org/10.1034/j.1399-3054.1990.790106.x.

[4] N. BREDMOSE and J. HANSEN, "Topophysis affects the Potential of axillary bud growth, fresh biomass accumulation and specific fresh weight in single-stem roses (Rosa hybridaL.)," Annals of Botany, vol. 78, pp. 215-222, 1996.Available at: https://doi.org/10.1006/anbo.1996.0115.

[5] I. A. Tamas, "Hormonal regulation of apical dominance, in," ed Dordrecht: Plant Horm., Springer Netherlands, 1995, pp. 572597.

[6] C. T. Costa, M. R. Almeida, C. M. Ruedell, J. Schwambach, F. S. Maraschin, and A. G. Fett-Neto, "When stress and development go hand in hand: main hormonal controls of adventitious rooting in cuttings," Front. Plant Sci, vol. 4, p. 133, 2013.Available at: https://doi.org/10.3389/fpls.2013.00133.

[7] M. A. Otiende, J. O. Nyabundi, K. Ngamau, and P. Opala, "Effects of cutting position of rose rootstock cultivars on rooting and its relationship with mineral nutrient content and endogenous carbohydrates," Sci. Hortic. Amsterdam, vol. 225, pp. 204212, 2017.Available at: https://doi.org/10.1016/j.scienta.2017.07.009.

[8] E. Wali, A. Datta, R. P. Shrestha, and S. Shrestha, "Development of a land suitability model for saffron (Crocus sativus L.) cultivation in Khost Province of Afghanistan using GIS and AHP techniques," Archives of Agronomy and Soil Science, vol. 62, pp. 921-934, 2016.Available at: https://doi.org/10.1080/03650340.2015.1101519.

[9] J. A. Dieleman, F. W. Verstappen, and D. Kuiper, "Bud break and cytokinin concentration in bleeding sap of Rosa hybrida as affected by the genotype of the rootstock," Journal of Plant Physiology, vol. 152, pp. 468-472, 1998.Available at: https://doi.org/10.1016/s0176-1617(98)80265-4.

[10] F. Al-Saqri and P. Alderson, "Effects of IBA, cutting type and rooting media on rooting of Rosa centifolia," Journal of Horticultural Science, vol. 71, pp. 729-737, 1996.Available at: https://doi.org/10.1080/14620316.1996.11515453.

[11] N. Bredmose, K. Kristiansen, and B. Nielsen, "Propagation temperature, PPFD, auxin treatment, cutting size and cutting position affect root formation, axillary bud growth and shoot development in miniature rose (Rosa hybrida L.) plants and alter homogeneity," The Journal of Horticultural Science and Biotechnology, vol. 79, pp. 458-465, 2004.Available at: https://doi.org/10.1080/14620316.2004.11511790.

[12] N. Zieslin, H. Haaze, and A. Halevy, "Components of axillary bud inhibition in rose plants. II. The effect of bud position on degree of inhibition," Botanical Gazette, vol. 137, pp. 297-300, 1976.Available at: https://doi.org/10.1086/336874. 
[13] S. Hoad and R. Leakey, "Effects of pre-severance light quality on the vegetative propagation of Eucalyptus grandis W. Hill ex Maiden," Trees, vol. 10, pp. 317-324, 1996.Available at: https://doi.org/10.1007/p100009651.

[14] S. Patterson, "How to propagate roses using potatoes," 2018.

[15] R. Moe, "Propagation, growth and flowering of potted roses," Acta Hortic, vol. 197, pp. 35-50, 1973.Available at: https://doi.org/10.17660/actahortic.1973.31.4. 